\title{
Heat-Exercise Hyperpyrexia
}

\section{Lt Col J G Dickinson}

\author{
DM, FRCP, DTM \& H, RAMC, Consultant Physician \\ Queen Elizabeth Military Hospital, Stadium Road Woolwich, London SE184QH
}

SUMMARY: A fatal case of "heat stroke" occurring on exercise in temperate conditions is described. Possible mechanisms for increased susceptibility are discussed and aftention is drawn to a possible overlap with the malignant hyperpyrexia (MH) syndrome. The second day of strenuous exercise may be a time of special risk. More frequent consideration of dantrolene treatment in heat injury is suggested and the term "heat-exercise hyperpyrexia" is proposed to replace "heat stroke" and "exertional hyperpyrexia".

\section{Introduction}

With some exceptions such as the deaths that occur in elderly and undernourished people each year in Indian trains, there is invariably an element of exertion involved in cases of heat stroke. The clinical, laboratory and autopsy findings of exertional hyperpyrexia are identical with those of heat stroke, and different papers, somewhat confusingly, use these terms and variants of them interchangeably ${ }^{1,2}$. From simple physical and physiological principles, the risk of heat injury is increased both by exercise, which increases heat production, and by raised environmental temperature and humidity, which reduce heat loss. Other important factors which influence the balance of heat production and loss are clothing, drugs (such as anticholinergics, phenothiazines and diuretics), alcohol, fluid intake, body weight, direct sunlight, acclimatisation to heat and the presence of other febrile illness ${ }^{3,4}$. However, when account is taken of all these variables, there remains the impression that some individuals are exceptionally susceptible to the effects of exercise and heat. The tragic death of one such man is described below.

\section{Case Report}

The patient was a white, 21 year old infantry private belonging to the contingent of another army serving with the United Nations Force in Cyprus. He had been treated a year previously in his home country after collapsing with "heat stroke" on a Battle Fitness Test in moderate conditions, but details are not available. On 19 April 1988 he successfully completed the first half of a 2 day Battle Fitness Test involving a 10 mile forced march at a planned pace of 12 minutes/mile. In fact, because his platoon lost their way, they actually covered about 12 miles. Dress was tropical combat kit with soft hat, webbing and weapon. The second half of the test was identical and began at 0530 hours on 20 April. Measurements at nearby Nicosia airport at 0700 hours local time gave a dry bulb air temperature of $12^{\circ} \mathrm{C}$ $\left(53.6^{\circ} \mathrm{F}\right)$ and humidity of $88 \%$. A light rain was falling. Eight miles into the march he was found to be confused and was lagging behind. He soon collapsed. On arrival at the local medical centre about $\mathbf{3 0}$ minutes later he was unconscious, hot and had no evidence of sweating. Axillary temperature was $40.5^{\circ} \mathrm{C}$, respiration was laboured and his BP was $60 / 40 \mathrm{~mm} \mathrm{Hg}$. He was cooled with ice packs and given intravenous fluids. Sweating was noted at 0930 hours and he regained consciousness at 1000 hours, but his temperature was still $39^{\circ} \mathrm{C}$. At 1300 hours he had 4 or 5 grand mal convulsions which were treated with diazepam, naloxone and haloperidol. At 1630 hours, after transfer to hospital, his cardiovascular state was satisfactory and his BP was 950 $70 \mathrm{~mm} \mathrm{Hg}$. Although he initially responded to simple commands, he soon lost consciousness again. He waps treated with dexamethasone, cimetidine anf intravenous fluids but next day he was worse wit bilateral ankle clonus, transient changes in pupil size an $\$$ evidence of diffuse intravascular coagulation (DIC) Aeromedical evacuation to UK was arranged.

On arrival, he was unresponsive to voice but die respond to pain. The arms were flaccid but there was bilateral ankle clonus and plantar reflexes were extensor. There were no cranial nerve signs and optic fundi could not be seen. Jaundice was noted. Urine output remained satisfactory. Tests done in Cyprus and in UK showed thrombocytopenia (lowest $25 \times 10^{9} / 1$ ), bilirubinaemia (increasing to $357 \mathrm{mmol} / 1$ ), increased transaminases (over 14,000 iu/1), creatine phosphokinase $(17,850 \mathrm{iu} / 1)$ and lactic dehydrogenase $1,656 \mathrm{iu} / 1$, prolonged prothrombin time (272 seconds), increased fibrinogen degeneration products $(160 \mu \mathrm{g} / \mathrm{dl})$, low blood urea $(1.5 \mathrm{mmol} / 1)$ and only minor abnormalities of serum creatinine, alkaline phosphatase and serum albumin. White cell count $16.6 \times 10^{9} 1$. Chest X-ray, ECG, spinal fluid, CT scan of brain and initial blood gases were normal and blood was negative for malaria parasites. Serological tests for hepatitis A and B were negative.

His prognosis was considered to be extremely poor, especially as he continued to deteriorate with increasing jaundice, diminishing response, increasing pulse rate, variable but generally dilating pupils, and eventually decreased urine output, noisy respiration, falling arterial oxygen pressures and rising carbon dioxide pressures. He died at 1710 hours on 25 April. 


\section{Autopsy findings}

At post mortem, external examination showed the body of a heavily built young man with jaundice, oedema and priapism. The brain was oedematous and there was a small haemorrhage in the cerebellum. Both lungs showed extensive haemorrhagic pneumonia but without frank pus. There was a slight pericardial effusion and the heart showed a subendocardial haemorrhage and some petechiae. The liver was soft and friable, the spleen was congested and also friable, and the kidneys were slightly oedematous. The cause of death was certified as haemorrhagic bronchopneumonia and hepatic failure due to hyperthermia. Histopathology added little except that sweat glands were normal in number and architecture and the liver showed severe centrilobular necrosis and intrahepatic cholestasis.

\section{Discussion}

Because of the relatively low environmental temperature at which this illness occurred, efforts were made to find an alternative diagnosis to that of heat stroke. Hepatitis $\mathrm{A}$ and $\mathrm{B}$, meningitis and malaria were ruled out. In any case, the findings of DIC, thrombocytopenia, convulsions, and hepatic failure of sudden onset were highly suggestive of heat injury and the findings at autopsy provided strong corroboration ${ }^{5}$. The question remains as to why he should have suffered heat injury at a time when others were unaffected. A Summary Investigation by his own service established that he was of average fitness and did not take alcohol on the night before the test. There was a suggestion that he had "a bit of a cold" and he may have been taking an anticongestant but no container was subsequently found. He was certainly overweight (estimated Body Mass Index $28 \%$ (normal $20-25 \%$ ) and he had made efforts to reduce this. He was not a new arrival in Cyprus, although the exact date of posting is not available. There were no irregularities in the conduct of the test, and the administration of first aid and the speed of evacuation were considered satisfactory.

This man did not have anhidrosis. He was almost certainly not taking any drug that impaired sweating and heat loss was not unduly prevented by inappropriate clothing. Humidity was, however, quite high at $88 \%$. His history of collapse on the previous Battle. Fitness Test and his final, fatal illness suggest that he was at the extreme end of the spectrum of susceptibility to the effects of exercise and heat.

This case is not unique in occurring in relatively mild conditions. Parnell and Restall ${ }^{6}$ described a fatal case after only 15 minutes forced marching at $16.7^{\circ} \mathrm{C}$ and $87 \%$ relative humidity, and Hanson et $a l^{2}$ report a severe collapse after running $10 \mathrm{~km}$ at $16^{\circ} \mathrm{C}$ and $60 \%$ humidity. Such cases are sometimes called exertional hyperpyrexia $^{1}$, sometimes heat stroke $^{6,7}$ and sometimes exertional heat stroke ${ }^{2}$. Although anhidrosis is said to be present in exertional hyperpyrexia and absent in heat stroke $^{1}$, this is not a consistent difference and the preseno case certainly lacked sweating on initial examination and resumed sweating with treatment.

Hyperpyrexia is a common and important problem is military medicine. Henderson et al ${ }^{3}$ documented $1 \vec{g}$ severe cases in a Hong Kong summer and even im Aldershot there were 40 admissions from heat-relate 9 illness in 38 months ${ }^{6}$. Training in inappropriate clothin has led to death ${ }^{1}$ and this has caused public concern ${ }^{8,9}$ The British Army uses the Wet Bulb Globe Tempera? ture Index to control physical exercise in warm humi conditions $^{3}$, but neither this nor any other current guidelines would have saved the patient described heres

The pathophysiological mechanisms in exertiona hyperpyrexia have recently been well reviewed ${ }^{1}$. A fałs in plasma volume occurs due to fluid loss by sweating and probably also because there is a shift of fluid from the extravascular to the intravascular space because of the breakdown of glycogen to smaller and more osmotically-active molecules. This hypovolaemia map lead to a vasoconstriction that helps to preserve्ह circulation but has the adverse effect of reducing heat loss through the skin. At a more advanced stage circulatory failure may lead to, or exacerbate, renal an $\Phi$ hepatic failure. Meanwhile, however, the denatura审o of protein due to unphysiological temperatures in क़h? tissues leads to direct injury. In the liver, this causer hepatic failure with possible encephalopat $\$$ y, hypoglycaemia and impaired blood clotting. Muscle ogeh damage may be of even greater importance, leadingta enzyme release, hyperkalaemia, hyperuricaemia an myoglobinaemia with resultant renal dames Rhabdomyolysis may also be the trigger for the $181 \%$ which commonly occurs. This causes hypofibrinoger aemia, thrombocytopenia, further renal damared multiple haemorrhages and the haemorrhagi pneumonia which often occurs as a terminal event $1,5,105$ A recent study has, however, shown that thrombon cytopenia may occur even in cases without DIC ${ }^{11}$. Brais function may be impaired by direct thermal injur (causing convulsions and oedema), by hepatic encephr? lopathy, by hypoglycaemia and by haemorrhage.

In the present case, no measurements of myoglobi were made, but the very high creatine phosphokinase levels suggested severe muscle damage. Liver failure DIC and celebral oedema were prominent mechanisms but renal function was preserved until the last few hour of life.

Little has been written about the possible reasons wh some individuals should be unduly susceptible to heat illness. They may simply have relatively inefficien. homeostatic mechanisms or there may be a specifig defect in the hypothalamus such that a rising core temperature is not detected or an appropriate response is not made. Another possibility is deficiency in the intracellular response to thermal threat, such as the production of heat shock proteins ${ }^{12}$. In relation to this it is of interest that death occurred in this case as in tw@ 
other documented cases ${ }^{1,6}$, on the second day of a strenuous test, thus raising the possibility that some such mechanism had been overstressed on the first day and had not had time to recover.

On the other hand, the possibility of excessive heat production might be considered. Attention has been drawn $^{13}$ to similarities between heat stroke and malignant hyperpyrexia (MH) and it has been suggested that individuals susceptible to MH may also be susceptible to heat stroke. Malignant hyperpyrexia is well known to anaesthetists as a condition of autosomal dominant inheritance in which anaesthetic agents (most commonly halothane) cause fulminating hyperpyrexia and death occurs in about $70 \%$ of cases. The lesion responsible is thought to be a defect in muscle fibres, probably in the sarcoplasmic reticulum, leading to abnormalities in the intracellular flux of calcium ions, increased muscle contraction and therefore heat production $^{14}$. Muscle can be tested in vitro for the defect, and affected muscle shows increased contractility on exposure to halothane or caffeine. In at least one case ${ }^{13}$ this abnormal response has been found in a subject who had recovered from heat stroke. Dantrolene sodium, a drug which acts in muscle to uncouple excitation and contraction, is useful in both treatment and prophylaxis of $\mathrm{MH}$, although its exact mechanism of action is unknown ${ }^{14}$. In heat stroke, dantrolene has been dramatically successful in some clinical cases ${ }^{13,15}$, but not in a canine model ${ }^{16}$.

\section{Conclusion}

This case report illustrates a Serviceman at the extreme end of a spectrum of susceptibility to the combined effects of environmental and exertional stress. Although training personnel should pay attention to all the adverse factors that have been described, it is doubtful, as with the effects of high altitude ${ }^{17}$, if any regulations can protect these very sensitive subjects. A high level of awareness and vigilance is required, particularly perhaps on the second day of strenuous exercise.

There is little justification for using the terms "heat stroke" and "exertional hyperpyrexia" in a mutually exclusive fashion. Clarity of thinking could be encouraged by using the term "heat-exercise hyperpyrexia" and by identifying the factors chiefly responsible. In this case, they would be strenuors exercise and humidity, possibly associated with obesit respiratory infection and the use of a decongestant. This patient may have had a predisposing condition, such $\mathrm{MH}$, and trial use of dantrolene might have been beneficial.

\section{REFERENCES}

1. JARMULOWICZ M R and BuChanAN J D. Exertional hyperpyrexia; case report and review of pathologicat mechanisms. J R Nav Med Serv 1988; 74: 33-8.

2. HANSON $\mathrm{G}$ and ZiMMERMAN $S \mathrm{~W}$. Exertional heat stroke $\stackrel{\overrightarrow{\mathrm{d}}}{\mathrm{m}}$ novice runners. JAMA 1979; 242: 154-7.

3. HENDERSON A, et al. Heat illness. A report of 45 cases from Hong Kong. JR Army Med Corps 1986; 132:76-84.

4. WOLFE $S$ M and BEHRMAN M. Heat stroke and community runs. Br Med J 1981; 282: 2060.

5. Chao T C, Siniah R and Pakiam J E. Acute heat stro deaths. Pathology 1981; 13: 145-56.

6. PARNELL $C J$ and RESTALL J. Heat stroke: a fatal case. Arêّ Emerg Med 1986; 3: 111-4.

7. WhITWORTH J A G and WOLFMAN M J. Fatal heat stroke $\overrightarrow{\mathrm{gg}}$ a long distance runner. $\mathrm{Br} \mathrm{Med} J$ 1983; 287: 948.

8. BRAHAMS D. Death of a soldier: accident or neglect? Lancet 1988; 1: 485. 9. REYNOLDS S. Heat stroke and army training. Lancet
1: 1222 .

10. RuBEL R. Case for diagnosis. Milit Med 1983; 148: 756म $\overrightarrow{\text {. }}$

11. Mustafa K Y, et al. Blood coagulation and fibrinolysis heat stroke. Br J Haematol 1985; 61: 517-23.

12. LINDQUIST $\mathrm{S}$. The heat stroke response. Ann Rev Bio बhidg 1986; 55: 1151-91.

13. Denborough $M$ A. Heat stroke and maligmant hyperpyrexia. Med J Aust 1982; 1: 204-5.

14. Ellis F R and HeFrron J J A. Clinical and bioche aspects of malignant hyperpyrexia. In: ATKINSON 8 , ADAMS A P. eds. Recent advances in anaesthesia analgesia 15. Edinburgh: Churchill Livingstone, 1985; $17 \frac{7}{-}$ 208.

15. LYDIATT J S and HILL G E. Treatment of heat stroke whin dantrolene. JAMA 1981; 246; 41-2.

16. AMSTERDAM J T, et al, Dantrolene sodium for treatment $\vec{g} f$ heat stroke victims: lack of efficiency in a canine mode. Am J Emerg Med 1986; 4: 399-405.

17. Dickinson J G. High altitude cerebral oedema: cerebial acute mountain sickness. Seminars in Respiratory Medici⿳⺈ $1983 ; 5: 151-58$. 